\title{
Multiple Small Bowel Perforations in a Patient of Chronic Myeloid Leukemia on Imatinib
}

\begin{abstract}
Chronic myeloid leukemia (CML) is a clonal hematopoietic disorder caused by an acquired genetic defect in a pluripotent stem cell. A series of discoveries led to the recognition that the BCR-ABL protein, which results from a reciprocal translocation involving chromosomes 9 and 22, has a central role in the pathogenesis of chronic myelogenous leukemia. The BCR-ABL protein functions as a constitutively activated tyrosine kinase (TK) and this knowledge led to the development of imatinib (STI-571), a drug that specifically inhibits the BCR-ABL TK. Common side effects of imatinib are low blood counts, nausea and vomiting, edema (swelling of the face, feet, and hands), muscle cramps and bone pain, diarrhea, hemorrhage, skin rash, and fever. Headache, fatigue, joint pain, indigestion, and abdominal pain are occasionally seen, and liver toxicity is a rare complication. We here report a case of multiple small bowel perforations in a patient of $\mathrm{Ph}^{+\mathrm{ve}}$ chronic myeloid leukemia-chronic phase on imatinib. Bowel perforation is a known complication for targeted therapy agents like bevacizumab, sunitinib, and sorafenib, which act on vascular endothelial growth factor receptor but imatinib having no anti VEGF receptor activity leading to such complication is a mystery. Physician treating their patient with imatinib should be aware of this complication and should act accordingly.
\end{abstract}

Keywords: Antivascular endothelial growth factor receptor, bowel perforation, chronic myeloid leukemia, imatinib, tyrosine-kinase inhibitor

\section{Introduction}

Here is discussion of an interesting case of a patient who is a known case of chronic myeloid leukemia-chronic phase (CP) on imatinib presenting in the emergency surgical unit with multiple small bowel perforations. Can multiple small bowel perforations be attributed as a rare complication of imatinib drug therapy or other differential diagnosis of bowel perforations to be considered along with accelerated phase of disease and granulocytic sarcoma with necrosis?

In May 2001, imatinib mesylate ${ }^{[1]}$ was approved by the Food and Drug Administration (FDA) for the treatment of patients with chronic myeloid leukemia (CML). Imatinib mesylate is a 2-phenylaminopyrimidine compound that specifically interacts with the adenosine triphosphate (ATP)-binding site of multiple tyrosine kinases (TKs) including BCR-ABL (an aberrant TK resulting from a fusion protein product of the acquired Philadelphia

This is an open access journal, and articles are distributed under the terms of the Creative Commons Attribution-NonCommercial-ShareAlike 4.0 License, which allows others to remix, tweak, and build upon the work non-commercially, as long as appropriate credit is given and the new creations are licensed under the identical terms.

For reprints contact: WKHLRPMedknow_reprints@wolterskluwer.com chromosome identified in $>90 \%$ of patients with CML), ABL-related gene product, and certain subgroup III receptor TK (c-kit receptor, platelet [PLT] derived growth factor receptor [PDGFR], and stem cell factor receptor).

Common side effects of imatinib are low blood counts, nausea and vomiting, edema (swelling of the face, feet, and hands), muscle cramps and bone pain, diarrhea, hemorrhage, skin rash, and fever. Headache, fatigue, joint pain, indigestion, and abdominal pain are occasionally seen, and liver toxicity is a rare complication. ${ }^{[2]}$ We here report a rare case of multiple bowel perforations in a patient on imatinib therapy for $\mathrm{PH}^{+v e} \mathrm{CML}-\mathrm{CP}$.

\section{Case Report}

A 26-year-old Asian male patient presented to our hospital 1.5 years back with a chief complaint of abdominal pain for 2 months; outside abdominal ultrasonogram showed mild hepatomegaly and huge splenomegaly which was later confirmed at our institute. Complete blood picture (CBP) showed

\footnotetext{
How to cite this article: Tadaiya MV, Tankshali RA. Multiple small bowel perforations in a patient of chronic myeloid leukemia on imatinib. Indian J Med Paediatr Oncol 2020;41:89-92.
}

\section{Mahavir Virendra Kumar Tadaiya, Rajen A Tankshali}

Department of Surgical Oncology, Gujarat Cancer and Research Institute, Ahmedabad, Gujarat, India

Submitted: 31-Mar-2018 Revised: 20-Aug-2018 Accepted: 18-Oct-2018 Published: 24-Apr-2020

Address for correspondence: Dr. Mahavir Virendra Kumar Tadaiya,

12/B, Puneet Park

Society, Shahibaug,

Ahmedabad - 380004 , Gujarat, India.

E-mail: mahavirtadaiya@gmail. com

Access this article online

Website: www.ijmpo.org

DOI: 10.4103/ijmpo.ijmpo_73_18

Quick Response Code:

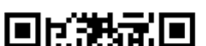


anemia and leukocytosis with white blood cell count (WBC) in range of $3.02 \mathrm{lac} / \mathrm{cmm}$. The patient was referred to our institute for further management. On further investigation patient - complete blood count: hemoglobin $(\mathrm{Hb})-7.9 \mathrm{gm} / \mathrm{dl}$, WBC - $3.02 \mathrm{lac} / \mathrm{cmm}$, PLT - $4.81 \mathrm{lac} / \mathrm{cmm}$, absolute neutrophil count - $2.57 \mathrm{lac} / \mathrm{ul}$, absolute lymphocyte count - 10,500/ul, erythrocyte sedimentation rate - $45 \mathrm{~mm} / \mathrm{h}$, uric acid - $11.24 \mathrm{mg} / \mathrm{dl}$, and lactate dehydrogenase - $1171 \mathrm{U} / \mathrm{L}$ [CBP, Table 1].

Bone Marrow Examination shows- hyper cellular marrow with myeloid hyperplasia and myelopeak.

Diagnosis - Chronic myeloid leukemia - CP.

Karyotype - 46, XY, t (9; 22) (q34; q11.2) Philadelphia chromosome is present.

The patient was diagnosed as a case of $\mathrm{PH}^{+v e}$ CML-CP started on treatment with imatinib $400 \mathrm{mg}$ once a day. The patient showed a very good response on treatment which was assessed by CBP at intervals of 1, 3, 9, and 14 months [CBP, Tables 2-5]. The patient responded well to imatinib therapy which is shown by lower leukocyte count as well-reduced liver and spleen size. A complete hematological remission was achieved as indicated by normal WBC and PLT counts and normal differential and disappearance of all symptoms and signs of CML. After 15 months of imatinib therapy, the patient presented with a complaint of oral ulcer along with penile base and scrotal ulcers; biopsy from all three sites done came out to be negative for malignancy. Laboratory reports showed $\mathrm{Hb}-7 \mathrm{gm} /$ dl, WBC - 28,700/cmm, and PLT - 49,000/cmm [CBP, Table 6]. Chest X-ray and ultrasound abdomen were normal.

A week later, the patient was referred to surgical department with acute abdomen for management. The patient had complained of pain in the abdomen for the last 4 days with abdominal distension. Chest X-ray showed free gas under the right dome of the diaphragm along with abdominal tenderness and tachycardia. Laboratory investigation showed $\mathrm{Hb}-6.3 \mathrm{gm} / \mathrm{dl}$, WBC $-24,300 / \mathrm{cmm}$, and PLT - 42,000/cmm [CBP, Table 7]. Preoperative resuscitation was done with blood transfusion, intravenous fluids, fresh-frozen plasma, and antibiotics. The patient shifted to operation theatre, and emergency laparotomy was performed. On examining abdominal cavity, multiple varying sizes ranging from 0.5 to $2.5 \mathrm{~cm}$, perforations found in distal ileum, caecum and proximal ascending colon [Figures 1 and 2]. Resection of affected part of the bowel along with ileotransverse anastomosis was done. Histopathological examination report showed- section of tissue with perforated \& ulcerated area shows mainly inflammatory infiltrates consists of lymphocytes, plasma cells, macrophages, histiocytes. Few ill defined granuloma $\&$ giant cells seen [Figures 3 and 4]. Necrosis was present. There was no evidence of malignancy. All 12 lymph nodes extracted were unremarkable.

\section{Table 1: CBP at time of initial presentation}

\begin{tabular}{lc}
\hline Hemoglobin & $7.90 \mathrm{gm} / \mathrm{dl}$ \\
RBC & $32.7 \mathrm{lakh} / \mathrm{cmm}$ \\
TLC & $3.02 \mathrm{lakh} / \mathrm{cmm}$ \\
Platelets & $4.81 \mathrm{lakh} / \mathrm{cmm}$ \\
Polymorphs & $85.20 \%$ \\
Eosinophils & $7.40 \%$ \\
Lymphocytes & $3.50 \%$ \\
Monocytes & $0.40 \%$ \\
Basophils & $3.50 \%$ \\
Absolute Neutrophil Count & $2.57 \mathrm{lakh} / \mathrm{ul}$ \\
Absolute Lymphocyte Count & $10,500 / \mathrm{ul}$ \\
\hline
\end{tabular}

\begin{tabular}{lc}
\hline \multicolumn{2}{c}{ Table 2: CBP after 1 month } \\
\hline Hemoglobin & $6.70 \mathrm{gm} / \mathrm{dl}$ \\
RBC & $30.1 \mathrm{lakh} / \mathrm{cmm}$ \\
TLC & $1.45 \mathrm{lakh} / \mathrm{cmm}$ \\
Platelets & $4.22 \mathrm{lakh} / \mathrm{cmm}$ \\
Polymorphs & $70.60 \%$ \\
Eosinophils & $15.50 \%$ \\
Lymphocytes & $13.50 \%$ \\
Monocytes & $0.40 \%$ \\
Basophils & - \\
Absolute Neutrophil Count & $1.02 \mathrm{lakh} / \mathrm{ul}$ \\
Absolute Lymphocyte Count & $19,700 / \mathrm{ul}$ \\
\hline
\end{tabular}

\begin{tabular}{lc}
\hline \multicolumn{2}{c}{ Table 3: CBP after 3 months } \\
\hline Hemoglobin & $10.80 \mathrm{gm} / \mathrm{dl}$ \\
RBC & $52.6 \mathrm{lakh} / \mathrm{cmm}$ \\
TLC & $5,400 / \mathrm{cmm}$ \\
Platelets & $2.251 \mathrm{lakh} / \mathrm{cmm}$ \\
Polymorphs & $52.00 \%$ \\
Eosinophils & $5.20 \%$ \\
Lymphocytes & $38.30 \%$ \\
Monocytes & $4.30 \%$ \\
Basophils & $0.20 \%$ \\
Absolute Neutrophil Count & $2,800 / \mathrm{ul}$ \\
Absolute Lymphocyte Count & $2,100 / \mathrm{ul}$ \\
\hline
\end{tabular}

\section{Discussion}

BCR-ABL Tyrosine Kinase Inhibitor's inhibit the BCRABL tyrosine kinase enzyme by competing with ATP binding to the kinase. Imatinib binds to an intracellular pocket located within TK, thereby inhibiting ATP binding and preventing phosphorylation and the subsequent activation of growth receptors and their downstream signal transduction pathways. This agent inhibits TK encoded by the BCR-ABL oncogene as well as receptor TKs encoded by the c-kit and PDGFR oncogenes. The first drug of this class was imatinib, which rapidly became the treatment of choice for patients with CML-CP after it was approved by the US FDA in 2001. Today, imatinib, nilotinib, dasatinib, bosutinib, and ponatinib are licensed for use in CML. ${ }^{[3]}$ 


\begin{tabular}{lc}
\hline \multicolumn{2}{c}{ Table 4: CBP after 9 months } \\
\hline Hemoglobin & $11.60 \mathrm{gm} / \mathrm{dl}$ \\
RBC & $54.1 \mathrm{lakh} / \mathrm{cmm}$ \\
TLC & $16,400 / \mathrm{cmm}$ \\
Platelets & $03.18 \mathrm{lakh} / \mathrm{cmm}$ \\
Polymorphs & $66.60 \%$ \\
Eosinophils & $03.20 \%$ \\
Lymphocytes & $20.90 \%$ \\
Monocytes & $07.60 \%$ \\
Basophils & $01.70 \%$ \\
Absolute Neutrophil Count & $10,900 / \mathrm{ul}$ \\
Absolute Lymphocyte Count & $3,400 / \mathrm{ul}$ \\
\hline
\end{tabular}

\begin{tabular}{lc}
\hline \multicolumn{2}{c}{ Table 5: CBP after 14 months } \\
\hline Hemoglobin & $11.70 \mathrm{gm} / \mathrm{dl}$ \\
RBC & 49 lakh/cmm \\
TLC & $4,600 / \mathrm{cmm}$ \\
Platelets & $1.07 \mathrm{lakh} / \mathrm{cmm}$ \\
Polymorphs & $36.40 \%$ \\
Eosinophils & $01.20 \%$ \\
Lymphocytes & $46.00 \%$ \\
Monocytes & $16.20 \%$ \\
Basophils & $0.20 \%$ \\
Absolute Neutrophil Count & $1,700 / \mathrm{ul}$ \\
Absolute Lymphocyte Count & $2,100 / \mathrm{ul}$ \\
\hline
\end{tabular}

Adverse effects occurring in $10 \%$ or more of patients include nausea, vomiting, edema, muscle cramps, diarrhea, gastrointestinal or central nervous system hemorrhage, musculoskeletal pain, rash, headache, fatigue, arthralgia, dyspepsia, myalgia, weight increase, pyrexia, abdominal pain, cough, dyspnea, anorexia, constipation, nasopharyngitis, night sweats, pruritus, epistaxis, hypokalemia, petechiae, pneumonia, and weakness. Changes in serum values showing- Severity Grade 3 or 4 hyperbilirubinemia, elevations in alkaline phosphatase, AlanineTransaminase, and AspartateTransaminase, severity Grade 3 or 4 neutropenia, anemia, or thrombocytopenia can also be seen. This case report brings into light a rare and important complication of imatinib therapy. The patient presented with life-threatening complication of multiple ileal perforations which is not a commonly known and listed adverse effect of imatinib therapy. Imatinib is a TK inhibitor which acts on BCR-ABL, c-kit, and PDGFR but not as antivascular endothelial growth factor inhibitor and thus puzzles the cause of bowel perforation. ${ }^{[4]}$

Nontraumatic causes of small bowel perforation are tuberculosis, typhoid, and Crohn's colitis. The patient does not show clinical features of above-mentioned diseases such as long-standing evening rise fever, cough, weight loss, abdominal pain, or history of medication for inflammatory bowel disease. Small bowel perforation due to imatinib therapy is a diagnosis of exclusion as we have no literature regarding perforated ulceration due to imatinib therapy.

\begin{tabular}{lc}
\hline \multicolumn{1}{c}{ Table 6: CBP after $\mathbf{1 5}$ months (at time of admission) } \\
\hline Hemoglobin & $7.00 \mathrm{gm} / \mathrm{dl}$ \\
RBC & $29.60 \mathrm{lakh} / \mathrm{cmm}$ \\
TLC & $28,700 / \mathrm{cmm}$ \\
Platelets & $49,000 / \mathrm{cmm}$ \\
Polymorphs & $80.20 \%$ \\
Eosinophils & - \\
Lymphocytes & $10.20 \%$ \\
Monocytes & $09.40 \%$ \\
Basophils & $0.20 \%$ \\
Absolute Neutrophil Count & $23,000 / \mathrm{ul}$ \\
Absolute Lymphocyte Count & $2,900 / \mathrm{ul}$ \\
\hline
\end{tabular}

\begin{tabular}{lc}
\hline \multicolumn{2}{c}{ Table 7: CBP one day before surgery } \\
\hline Hemoglobin & $6.30 \mathrm{gm} / \mathrm{dl}$ \\
RBC & $26.2 \mathrm{lakh} / \mathrm{cmm}$ \\
TLC & $24,300 / \mathrm{cmm}$ \\
Platelets & $42,000 / \mathrm{cmm}$ \\
Polymorphs & $83.40 \%$ \\
Eosinophils & - \\
Lymphocytes & $5.10 \%$ \\
Monocytes & $11.40 \%$ \\
Basophils & $0.10 \%$ \\
Absolute Neutrophil Count & $20,200 / \mathrm{ul}$ \\
Absolute Lymphocyte Count & $1,200 / \mathrm{ul}$ \\
\hline
\end{tabular}

A differential diagnosis of progression to accelerated phase needs to be considered, as at the time of admission, the patient has raised total leukocyte count along with thrombocytopenia. In general, accelerated phase is characterized by symptoms of fever, night sweat, weight loss, and bone pain. Multiple bowel perforations are not a mentioned complication.

Another differential can be extramedullary myeloid cell tumor (EMCT) or granulocytic sarcoma or chloroma. It is an extramedullary tissue mass of blast and immature myeloid cells. EMCT is more common in undifferentiated and minimally differentiated AML subtypes. Histopathological examination also does not show myeloid deposits. Blast crisis of chronic leukemia refers to a phase of chronic leukemia resembling an acute leukemia (blast $>30 \%$ ). Extramedullary blast crisis most commonly affects the skin, lymph nodes, spleen, bone, and central nervous system. ${ }^{[2]}$

\section{Conclusion}

Imatinib is a relatively safe drug being in use for the last 17 years. Imatinib is a very effective and first choice therapy for chronic myeloid leukemia. Adverse effects of imatinib are well tolerated, and therapy can be given for longer duration of time. However physician administering imatinib, should be aware of this could be fatal and rare but possible complication of bowel perforation due to imatinib therapy. A differential diagnosis of progression to 


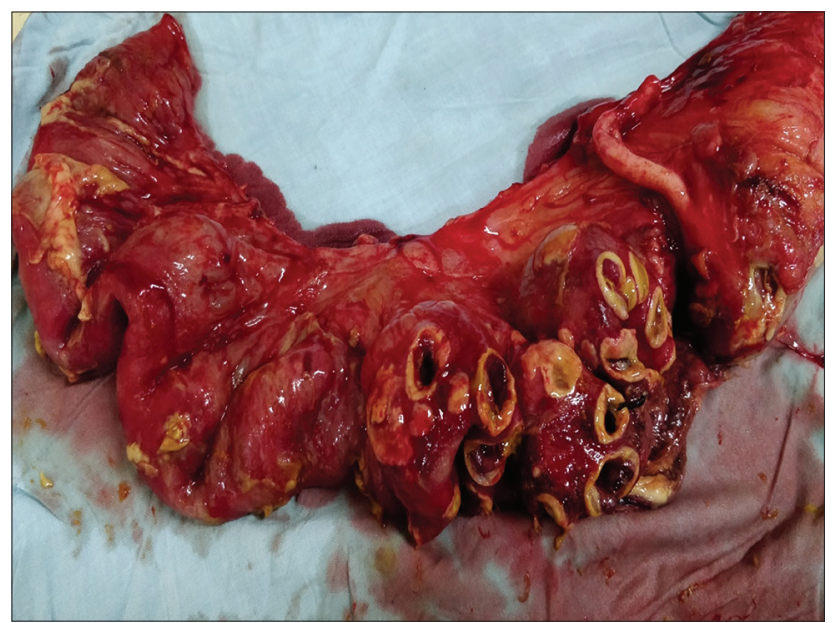

Figure 1: Specimen showing distal ileal perforations

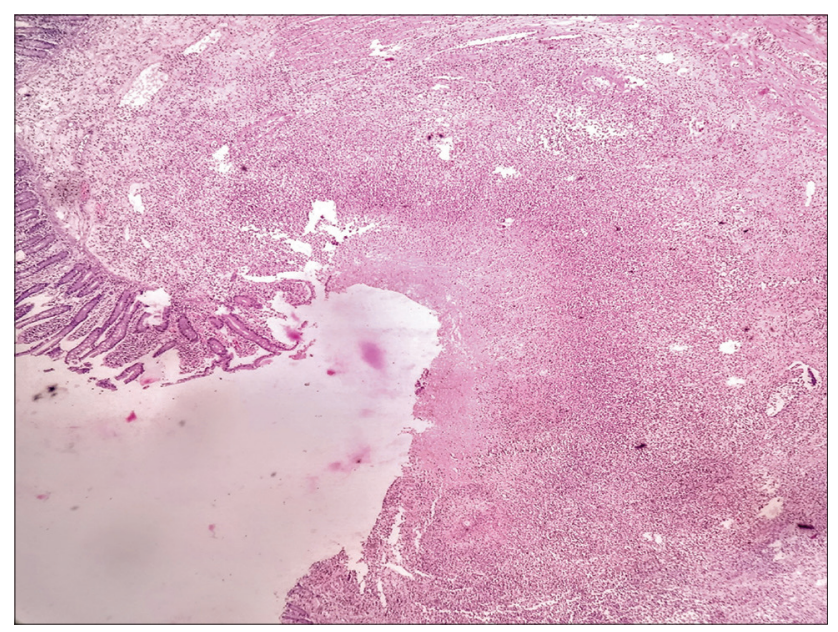

Figure 3: Microscopic examination of perforated bowel specimen a

accelerated phase and EMCT or granulocytic sarcoma or chloroma can be considered.

\section{Declaration of patient consent}

The authors certify that they have obtained all appropriate patient consent forms. In the form the patient(s) has/have given his/her/their consent for his/her/their images and other clinical information to be reported in the journal. The patients understand that their names and initials will not be published and due efforts will be made to conceal their identity, but anonymity cannot be guaranteed.

\section{Financial support and sponsorship}

Nil.

\section{Conflicts of interest}

There are no conflicts of interest.

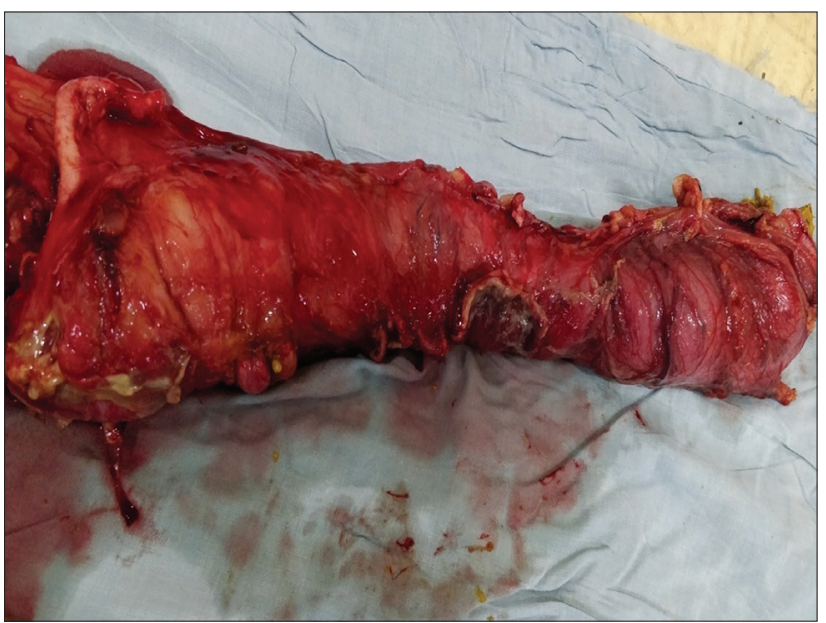

Figure 2: Specimen of resected ileum, ileo-caecal junction \& ascending colon

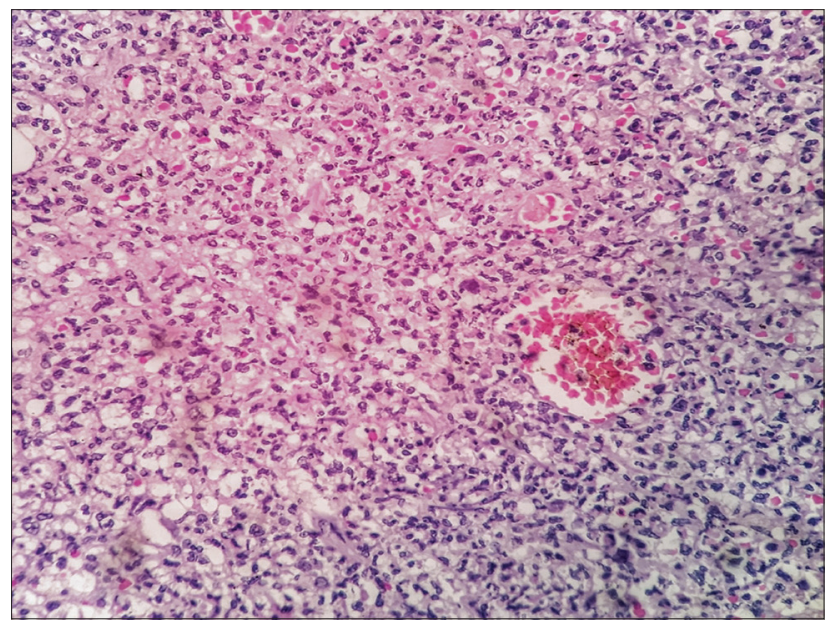

Figure 4: Microscopic examination of perforated bowel specimen b

\section{References}

1. Mohamed AN, Pemberton P, Zonder J, Schiffer CA. The effect of imatinib mesylate on patients with Philadelphia chromosome-positive chronic myeloid leukemia with secondary chromosomal aberrations. Clin Cancer Res 2003;9:1333-7.

2. Hoffman R, Benz EJ, Shattil SJ Jr., Furie B, Silberstein LE, McGlave P, et al. Hematology Basic Principles and Practice. $5^{\text {th }}$ ed., Ch. 69. Philadelphia: Elsevier Saunders; 2008. p. 1114-8.

3. Druker BJ, Marin D, DeVita, Hellman, Rosenbergs. Cancer Principles and Practice of Oncology. 10 $10^{\text {th }}$ ed., Ch. 109. Philadelphia: Wolters Kluwer Health; Chronic Myelogenous Leukemia, 2015. p. 1644-8.

4. McEvoy GK, editor. American Hospital Formulary Service - Drug Information 2003. Plus Supplements. Bethesda, MD: American Society of Health-System Pharmacists, Inc.; 2003. p. 1027. 